\title{
Forest fragmentation and matrix effects: the matrix does matter
}

When ecologists envision a traditional habitat fragmentation study, they usually conjure up an image of very discrete fragments, perhaps rectangular or even square, surrounded by a matrix of very different, inhospitable habitat. Patch equals habitat; matrix equals wasteland. We are well aware that real-world landscapes do not fit into such perfectly geometric, discrete packages. However, black and white dichotomies are easier to model, and these models are easily envisioned when we ponder effects of fragmentation.

So what happens to our predictions about species distribution patterns when the patch and the matrix are not all that different in habitat structure or habitat type? How does this change our expectations of traditional island biogeographical models or habitat fragmentation effects? How does it change expectations regarding dispersal between patches or survival and reproduction within the matrix? Vasconcelos et al. (2006) examined long-term effects of forest fragmentation on Amazonian ant communities and found that fragments supported fewer ant species per plot, fewer rare species, and the species on fragments represented a nested subset of those found in continuous forest. These sound like expected results. Following from the theory of island biogeography, we expect that species richness in habitat fragments is a function of patch size and degree of isolation. Fragments having significantly fewer rare species have also been reported by Golden \& Crist (1999). Nestedness has been reported in other habitat fragmentation studies, as exemplified for butterflies in experimentally fragmented successional grasslands (Holt et al., 1995) and for birds on isolated woodlots (Blake, 1991). However, in Vasconcelos et al. (2006) the difference between the number of species occurring in fragments and continuous forest was very small; the forest fragments harboured on average $85 \%$ of the species found in continuous forest despite very large differences in patch sizes between forest fragments and continuous forest.
Should we find these results surprising? Perhaps not, I would argue. My reasoning has to do with the influence of the area between the habitable patches, otherwise known as the matrix.

The Vasconcelos et al. (2006) paper provides an excellent example of how understanding the effects of fragmentation requires an understanding of the differences (and similarities) between the patch and matrix. The patches here are forest; the matrix habitat is savannah. So, the dominant vegetation is similar in patch and matrix. The species of trees may be different, but the overall habitat structure is not so dissimilar. How does the matrix habitat affect local diversity patterns in a fragment? A variety of investigators have been examining the effects of landscape context on local species distribution patterns. Ricketts (2001) coined the phrase 'the matrix matters' in a paper that examined butterfly communities and demonstrated that the composition of the matrix habitat can significantly influence effective isolation of habitat patches. Debinski et al. (2001) examined point diversity of butterflies within patches of different meadow types arrayed along a hydrological gradient. In landscapes where patch sizes are small relative to the movement patterns of the organism, the type of patch adjacent to the patch surveyed can influence both local species richness and incidence. We hypothesized that the mechanism for species enrichment was the movement of individuals between habitat patches, resulting in either spillover or habitat sampling by species that benefit from the resources in adjacent patches. Bender and Fahrig (2005) examined the effects of matrix structure on patch movement relative to patch size and isolation using simulation models and translocation studies of small mammals. They found that patch size and isolation are poor predictors of interpatch movement when the landscape matrix is heterogeneous and organisms respond to boundaries between different matrix cover types. Thus, matrix effects on local diversity patterns can be significant. In the case of ants in the rain forests, a matrix of savanna may be much less harsh of a matrix habitat than a clearcut or grassland.

One might ask secondly about the size of the patches. The patches ranged from 2.4 to 361 ha, although only two were larger than 100 ha (Vasconcelos et al., 2006). For small invertebrates, a couple of hectares might be expected to be adequate to sustain a population. However, Didham (1997) found that areas as large as 100 ha cannot maintain an intact terrestrial invertebrate assemblage in Central Amazonia. The edge penetration distances of most microclimatic factors, which invertebrates can be particularly sensitive to, are estimated at approximately $100 \mathrm{~m}$ (Didham, 1997). Therefore some of the smaller patches may or may not meet these minimum size estimates needed to minimize edge effects, depending upon patch shapes. Vasconcelos et al. (2006) found that patch shape and degree of isolation were not significant factors affecting species richness and composition of ant communities, but fragment area did have some influence on species composition. It may be that these fragmentation plots with 'older' edges (those created by earlier fragmentation events) may have less significant effects in terms of microclimate.

This system also moves us to think differently about effects of time since isolation. Vasconcelos et al. (2006) note that the pattern of forest islands isolated by savanna in their study area has existed since at least the middle of the 19th century. Fragments that have been isolated for such a long period of time are rare. As such, one would expect that species distributions would now be at some sort of equilibrium. These are not forest fragments surrounded by clearcuts where short-term crowding effects are followed by 'relaxation' of the species number to an equilibrium value (e.g. Kattan et al., 1994). But how might time have acted to increase species numbers in fragments? Perhaps time and the rare probability of 
chance events may be acting in concert with distance effects to increase species richness. The issue of time in the context of fragmentation studies is a topic that warrants additional study. Most experimentally constructed fragmentation studies are limited in their ability to examine effects of time (Debinski \& Holt, 2000). However, examining issues of species loss versus species gains in fragments through time, especially from the context of those species that may find new edge conditions favourable, is an area where future research could provide important new insights into both the mechanisms and the effects of fragmentation.

Vasconcelos et al. (2006) describe a system where the fragments are on average less than $300 \mathrm{~m}$ apart (none was more than $1100 \mathrm{~m}$ from another area of forest). This distance may be considered rather short even for insects such as ants. Mating queens are winged, and some ant colonies also move via 'budding' when colonies split into two. Argentine ants have been documented to spread $150 \mathrm{~m}$ a year by budding, but jump-dispersal distances average three orders of magnitudes higher (Suarez et al., 2001). The open savanna areas may represent somewhat of a barrier given that microhabitat conditions are probably drier, but over a period of 150 years, even rare dispersal events increase in probability.

So in essence the findings of Vasconcelos et al. (2006) are not so surprising if we remove ourselves from the traditional image of dichotomous patch and matrix landscapes. The combination of issues such as a moderately hospitable matrix type, a rather short distance between patches, and 'old' edges may all be acting together to allow for smaller differences between the forest fragments and continuous forest patches. One of the most interesting aspects of this study is that the patches are naturally, rather than anthropogenically, fragmented. Because the landscape is relatively undisturbed, there are fewer issues related to invasive species and significant differences in microclimate at the edges. This may make all the difference. The natural fragmentation of the Vasconcelos patches and the age of the patches makes the work important for understanding and interpreting long-term biogeographical trends in relatively unimpacted communities. It may also provide some guidance in understanding how we might manage landscapes to minimize anthropogenically induced fragmentation and edge effects. In the Manaus, Brazil study, ironically one of the most difficult aspects of this experimental fragmentation treatment was keeping the fragments isolated. Regeneration of second growth in the 'matrix' occurred so quickly that steps needed to be taken at regular intervals to cut back the regrowth to keep patches 'isolated' (Debinski \& Holt, 2000). Maybe it is time to more rigorously compare fragmentation effects where we have both patches with a clean (e.g. clearcut) matrix and those with more messy edges of a regrowth matrix. The implications of such research will provide important guidance in the management of corridors and reserves. Rather than considering reserves and corridors in a black and white dichotomy of habitat and non-habitat matrix, we may find it informative to consider effects of various types of matrix around these protected areas.

DiAne M. DeBinski Department of Ecology, Evolution, and Organismal Biology, 253 Bessey Hall, Iowa State University, Ames, IA 50011, USA E-mail:debinski@iastate.edu

\section{REFERENCES}

Bender, D.J. \& Fahring, L. (2005) Matrix structure obscures the relationship between interpatch movement and patch size and isolation. Ecology, 86, 1023-1033.

Blake, J.G. (1991) Nested subsets and the distribution of birds on isolated woodlots. Conservation Biology, 5, 58-66.

Debinski, D.M. \& Holt, R.D. (2000) Habitat fragmentation experiments: a global survey and overview. Conservation Biology, 14, 342-355.

Debinski, D.M., Ray, C. \& Saveraid, E.H. (2001) Species diversity and the scale of the landscape mosaic: do scales of movement and patch size affect diversity? Biological Conservation 98, 179-190.

Didham, R.K. (1997) The influence of edge effects and forest fragmentation on leaf litter invertebrates in central Amazonia. Tropical forest remnants: ecology, management, and conservation of fragmented communities (ed. by W.F. Laurance and
R.O. Bierregaard Jr), pp. 55-70. University of Chicago Press, Chicago, IL.

Golden, D.M. \& Crist, P.O. (1999) Experimental effects of habitat fragmentation on old-field canopy insects: community, guild and species responses. Oecologia, 118, 371-380.

Holt, R.D., Debinski, D.M., Diffendorfer, J., Gaines, M., Martinko, E., Robinson, G. \& Ward, G. (1995) Perspectives from an experimental study of habitat fragmentation in an agroecosystem. Ecology and integrated farming systems (ed. by D.M Glen, M.P. Greaves and H.M. Anderson), pp. 147-175. John Wiley and Sons, Chichester.

Kattan, G.H., Alvarez-Lopez, H. \& Giraldo, M. (1994) Forest fragmentation and bird extinctions: San Antonio 80 years later. Conservation Biology, 8, 138-146.

Ricketts, T.H. (2001) The matrix matters: effective isolation in fragmented landscapes. The American Naturalist, 158, 8799.

Suarez, A.V., Holway, D.A. \& Case, T.J. (2001) Patterns of spread in biological invasions dominated by long-distance jump dispersal: insights from Argentine ants. Proceedings of the National Academy of Sciences of the United States of America, 98, 1095-1100.

Vasconcelos, H.L., Vilhena, J.M.S., Magnusson, W.E. \& Albernaz, A.L.K.M. (2006) Long-term effects of forest fragmentation on Amazonian ant communities. Journal of Biogeography, 33, 1348-1356.

\section{BIOSKETCH}

Diane M. Debinski is an associate professor in the Department of Ecology, Evolution, and Organismal Biology at Iowa State University. Her primary interests are in the areas of conservation biology, restoration ecology and landscape ecology. Her field research focuses on prairie restoration, habitat fragmentation and the effects of global climate change.

Editor: Dov Sax 